of some laboratories to subject the test specimens to more intensive study than would be given to routine specimens passing through the laboratory, thereby ensuring a satisfactory result. A final article deals with practical details of quality control and contains a lengthy appendix.

Though uneven in matter and method, the book contains no disturbingly contrary views. It is not a text book, and the lack of conformity in bacteria used for sterility tests (table 2, page 32 and table 5, page 68) need not disturb. It is, however, distracting to find that the difference of means is not always equal to the mean of differences (table 5, page 76). More than half the articles have a dozen or more references, and there is an index.

P. B. CRONE

\title{
Classification of bacteria
}

By F. Kauffman. 1975, Copenhagen: Munksgaard. Pp. 169. $£ 17 \cdot 00$.

This monograph is subtitled " A realistic scheme with special reference to the classification of salmonella and escherichia species". It is in fact an updated version of "Serological diagnosis of Salmonella-species " (Munksgaard, Copenhagen, 1972), with the addition of a section on Escherichia, also based on previous volumes.

The section on classification in general (chapter A) is a statement of Kauffmann's credo. As such it is interesting and something of a curiosity, but not particularly useful. It claims, among other things, that Year 1 of bacteriological nomenclature should be 1900 and not 1753 . Chapter B gets down to some cases, and points out that, so far as the enterobacteria are concerned, classification is based on serotype rather than biotype, since different serotypes may belong to the same biotype. Quite true. But this has been accepted for many years. It has also been accepted that serotypes can be still further subdivided into different biotypes and phage types (the cacophonous term "phago-type" is used here). It is no novelty that the primary step on this diagnostic road is serotyping. The whole train of classification manoeuvres originated in medical expediency and the search for epidemiological markers.

Chapters $\mathbf{A}$ and $\mathbf{B}$ are followed by a treatise on the antigenic structure and practical diagnosis of salmonella serotypes. Somatic antigens 1 to 65 are listed, together with the type strains used for the preparation of the respective agglutinating sera needed for their detection.

The $\mathrm{H}$ antigens are similarly dealt with. Practical details are provided for the preparation of polyvalent agglutinating sera, with the object of identifying $\mathrm{O}$ and $\mathrm{H}$ groups to which an unknown salmonella belongs. Tests can then be carried out with the individual group components for precise identification.

A comprehensive list of salmonellae is provided.

This section is followed by that on Escherichia. The genus is defined, as with the salmonellae, as " a large group of related species (Kauffmann's italics) designated by their antigenic formulae ". Escherichia coli is cited as the only sub-genus so far recognised. The genus is further defined biochemically in terms of reactions such as sugar fermentation, absence of gelatin liquefaction, lack of $\mathrm{H}_{2} \mathrm{~S}$ production, negative Voges-Proskauer test and so on. The biochemical reactions of type $E$. coli are given as an example. There is a discussion of the $\mathrm{K}$ antigens, and the $\mathrm{L}, \mathrm{A}$ and $\mathrm{B}$ subdivisions of these envelope or capsular antigens are described in some detail. Practical details are given of the preparation of bacterial suspensions for use as $\mathrm{O}, \mathrm{K}$ or $\mathrm{H}$ antigens for serum production and agglutination tests. There are tables of Escherichia groups classified on the basis of antigenic structure.

In a section on pathogenic Escherichia it is pointed out that there is a close serological relationship between various Escherichia, Arizona and Salmonella $\mathrm{O}$ serotypes and in a few instances between $\mathrm{K}$ antigens, but there are no $\mathrm{H}$ antigenic similarities between Escherichia and Salmonella. Arizona is designated as Salmonella subgenus III.

The possible significance of $\mathrm{L}$ antigens in relation to pathogenicity of Escherichia is debated. Antigen L1 appears to predominate in strains causing meningitis.

Fimbrial antigens, protein in nature, are of possible importance in aiding pathogenicity by enabling the organisms to adhere to mucosal surfaces. Although fimbrial antigen 88 is stated to be transferable (sic!) the probable importance of plasmids as contributors to pathogenicity in Escherichia escapes mention. 
The monograph ends with a repetition of the opening general claims concerning classification. In effect it suggests that Bergey's Manual of Determinative Bacteriology should be thrown out of the window, and that Kauffmann's propositions are those to follow in classification. The truth probably lies somewhere between these two extremes, with the additional use of new technologies.

\section{E. S. ANDERSON}

\section{The color atlas of intestinal parasites}

By F. M. SPENCER and L. S. MonRoe. 1975. Revised 6th printing. Springfield, Illinois: Charles C. Thomas. Pp. xvii and 158. US $\$ 14.75$.

Although described as a colour atlas, this book contains five chapters of text in addition to an excellent collection of colour photomicrographs of parasitic forms seen in faeces. Written by clinicians with an obvious interest in laboratory medicine, the book draws attention to the growing importance of parasitic intestinal infections in non-tropical areas, and provides an up-to-date, authoritative and detailed guide to the laboratory diagnosis of these conditions. Methods used in the collection, preservation, fixation, staining and examination of specimens are fully described, and the currently available serological tests are reviewed and discussed.

Three chapters are devoted respectively to the intestinal protozoa, the intestinal helminths, and to confusing objects (" pseudoparasites") that might be found in faeces. Brief comments are made on the geographical distribution, pathogenicity, frequency and importance of each species of parasite, and, where appropriate, clinical and pathological features of the corresponding diseases are given. The stated aim of the authors is to provide an aid to diagnosis rather than a comprehensive textbook of parasitology, and no detailed descriptions are therefore given of adult helminths, life cycles or epidemiology, and only the intestinal parasites are considered.

Because diagnosis of the parasitic intestinal diseases depends so largely upon the ability of the microscopist to recognise and identify the many different structures that may be present in faeces in health or disease, it is important that any textbook illustrations that may be studied for comparison should clearly depict the true appearances of these structures as they are likely to be seen in clinical specimens. This requirement is amply fulfilled by the large collection of high quality photomicrographs in the colour atlas section of the book, and the authors may justifiably claim to have produced an extremely practical diagnostic manual for use in the clinical laboratory.

A. L. Jeanes 